\title{
DIMENSI METRIK DARI GRAF BUCKMINSTERFULLERENE
}

\author{
ADEK HAYATI PUTRI, LYRA YULIANTI, DES WELYYANTI \\ Program Studi S1 Matematika, \\ Fakultas Matematika dan Ilmu Pengetahuan Alam, Universitas Andalas, \\ Kampus UNAND Limau Manis Padang, Indonesia. \\ email : adkhaput10@gmail.com
}

Diterima 29 November 2019 Direvisi 3 Desember 2019 Dipublikasikan 28 Desember 2019

\begin{abstract}
Abstrak. Penelitan ini bertujuan menentukan dimensi metrik dari salah satu graf Fullerne yaitu graf Buckminsterfullerene yang memiliki 60 titik. Satu-satunya graf dengan dimensi metrik satu adalah graf lintasan $P_{n}$ dengan $n \geq 2$ sehingga tidak mungkin graf Buckminsterfullerene memiliki dimensi metrik satu. Dari hasil penelitian ini diperoleh bahwa dimensi metrik dari graf Buckminsterfullerene adalah tiga.

Kata Kunci: Dimensi metrik, himpunan pemisah, graf Fullerene, graf Buckminsterfullerene
\end{abstract}

\section{Pendahuluan}

Teori graf merupakan salah satu cabang ilmu matematika yang pertama kali diperkenalkan oleh Leonhard Euler pada abad ke-18. Salah satu kajian dalam teori graf adalah dimensi metrik yang pertama kali diperkenalkan oleh F. Harary dan R. A Milter pada tahun 1976. Akhter dkk. [1] menunjukkan bahwa dimensi metrik dari graf $(3,6)$-Fullerene dan $(4,6)$-Fullerene adalah tiga. Pada [1]. diberikan masalah terbuka yang berkaitan dengan graf $(5,6)$-Fullerene yang memuat graf $C_{5}$ dan $C_{6}$. Salah satu bentuk sederhana dari graf $(5,6)$-Fullerene adalah graf Buckminsterfullerene. Penelitian ini bertujuan menentukan dimensi metrik dari salah satu graf Fullerene yaitu graf Buckminsterfullerene yang memiliki 60 titik.

\section{Landasan Teori}

\subsection{Definisi dan Terminologi Teori Graf}

Graf $G$ adalah pasangan himpunan $(V(G), E(G))$ dinotasikan $G=(V, E)$, dengan $V(G)$ adalah suatu himpunan berhingga titik (vertex) yang tak kosong, kardinalitas dari $V(G)$ yang dinotasikan dengan $|V(G)|$ disebut orde dan $E(G)$ adalah himpunan sisi (edge) yang menghubungkan dua titik pada graf $G$ tersebut, kardinalitas dari $E(G)$ yang dinotasikan dengan $|E(G)|$ disebut ukuran. Jalan (walk) dari titik $v_{0}$ ke titik $v_{n}$ di $G$ adalah barisan berhingga dari titik-titik dan sisi-sisi di $G$ dapat 
ditulis $v_{0}, e_{1}, v_{1}, e_{2}, e_{n}, v_{n}$ sedemikian sehingga $v_{i-1} \in E(G)$ untuk $i=1,2,3,, n$. Jika titik-titik dan sisi-sisi dari jalan yang dilewati berbeda maka dikatakan lintasan (path). Banyaknya sisi yang terdapat pada suatu lintasan disebut panjang lintasan. Jarak adalah panjang lintasan terpendek dari titik $u$ ke $v$, dinotasikan $d(u, v)$.

Diameter suatu graf terhubung $G$ adalah maksimum jarak antara titik-titik di $G$, dimana graf terhubung adalah graf yang setiap pasang titik pada $u, v \in V(G)$ terdapat suatu lintasan yang menghubungkan $u$ dan $v$. Graf regular adalah graf yang setiap titiknya berderajat sama, dimana derajat suatu titik di $G$ adalah banyaknya sisi yang terkait dengan v, dinotasikan dengan $\operatorname{deg}(v)$. Graf planar adalah graf yang dapat digambarkan pada bidang datar dengan sisi tidak saling memotong (bersilangan).

\subsection{Graf Fullerene}

Fullerene adalah molekul polihedral yang seluruhnya terbuat dari atom karbon. Molekul polihedral adalah kumpulan dari beberapa atom yang ada didalam susunan tertentu yang diperlukan oleh gaya kimia atau ikatan kimia. Fullerene dapat direpresentasikan dengan atom sebagai titik dan ikatan antar atom sebagai sisi [2]. (Lihat Gambar 1).

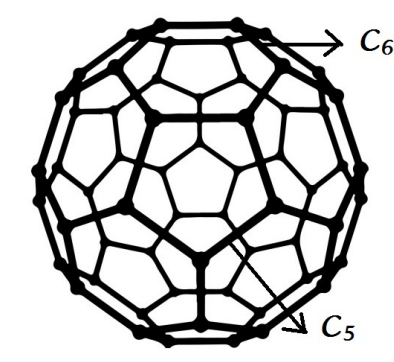

Gambar 1. Contoh Fullerene

Dari Gambar 1 dapat dilihat jika Fullerene tersebut dikonstruksi dalam bidang datar maka akan menghasilkan Graf Fullerene yang memuat graf $C_{5}$ atau $C_{6}$. Graf Fullerene adalah graf yang setiap titiknya berderajat tiga dan memiliki sisi yang tidak saling memotong. Jika graf Fullerene mempunyai titik $n=20$ maka graf tersebut dinamakan graf Dodecahedral dan jika graf Fullerene mempunyai titik $n=60$ maka graf tersebut dinamakan graf Buckminsterfullerene [2]. (Lihat Gambar 2)

\subsection{Graf Buckminsterfullerene}

Graf Buckminsterfullerene diperoleh dari beberapa graf cycle dengan cara sebagai berikut. Graf $C_{5}$ berada pada bagian terluar dan bagian dalam, dinotasikan dengan $C_{5}$ dan $C_{5}^{*}$. Graf $C_{5}$ dan $C_{5}^{*}$ dihubungkan oleh sisi pada masing masing titiknya, 


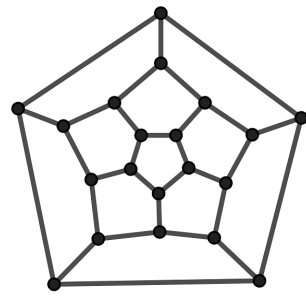

(a)

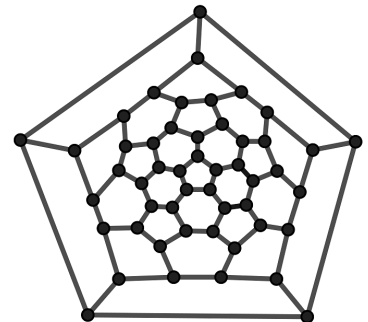

(b)

Gambar 2. (a) Graf Dodecahedral, (b) Graf Buckminsterfullerene

setiap sisi pada graf $C_{5}^{*}$ diberi penambahan dua titik, masing-masing titik pada graf $C_{5}^{*}$ dihubungkan oleh sisi, dimana pada setiap sudutnya membentuk $C_{5}$ yang baru dan diantara $C_{5}$ tersebut membentuk $C_{6}$ yang baru. Hubungkan setiap titik pada $C_{5} *$ dengan sisi sehingga membentuk graf Buckminsterfullerene. (Lihat Gambar 3).

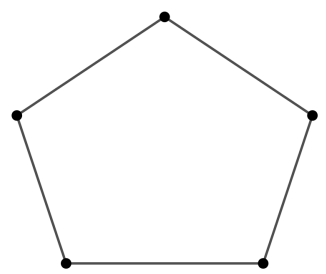

(a). $C_{5}$ di bagian luar

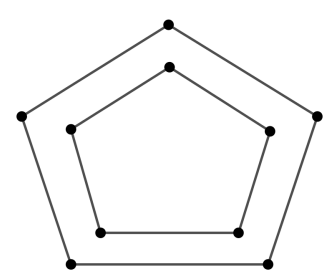

(b) $\mathrm{C}_{5} *$ bagian dalam

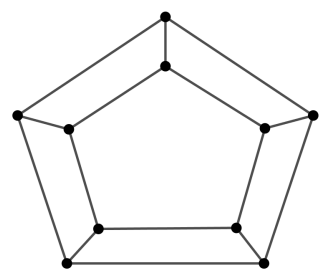

(c) $\mathrm{C}_{5}$ dan $\mathrm{C}_{5} *$ dihubungkan oleh satu sisi
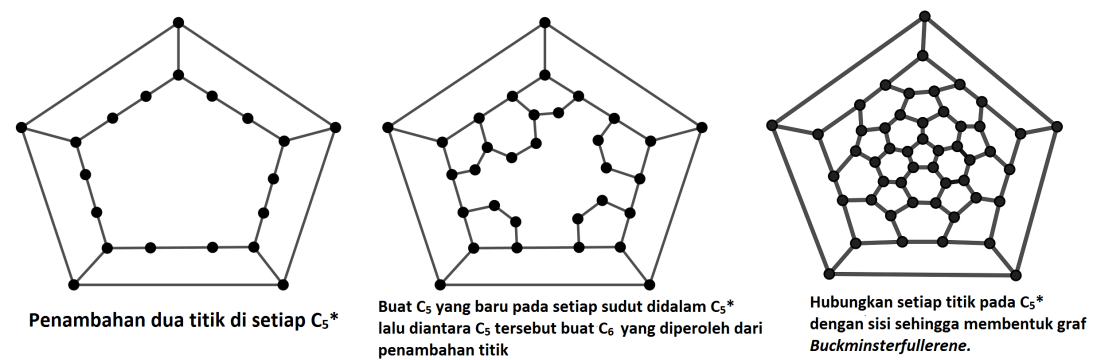

Gambar 3. Tahapan Membentuk Graf Buckminsterfullerene

Dari Gambar 3 diperoleh graf $C_{5}$ dan $C_{6}$ seminimal mungkin dengan titik sebanyak 60 [2]. Berdasarkan Gambar 2.3.2 dapat dilihat bahwa Graf Buckminsterfullerene berasal dari $C_{5} \cup C_{15} \cup C_{20} \cup C_{15}^{*} \cup C_{5}^{*}$ dengan penambahan beberapa sisi 
sebagai berikut:

$$
\begin{aligned}
& V(G)=\left\{v_{i} \mid 1 \leq i \leq 5\right\} \cup\left\{w_{j} \mid 1 \leq j \leq 15\right\} \cup\left\{x_{k} \mid 1 \leq k \leq 20\right\} \\
& \cup\left\{y_{j} \mid 1 \leq j \leq 15\right\} \cup\left\{z_{i} \mid 1 \leq i \leq 5\right\} . \\
E(G)= & \left\{v_{l} v_{l+1} \mid 1 \leq l \leq 4\right\} \cup\left\{v_{1} v_{5}\right\} \cup\left\{w_{m} w_{m+1} \mid 1 \leq m \leq 14\right\} \cup\left\{w_{1} w_{15}\right\} \\
& \cup\left\{x_{n} x_{n+1} \mid 1 \leq n \leq 19\right\} \cup\left\{x_{1} x_{20}\right\} \cup\left\{y_{m} y_{m+1} \mid 1 \leq m \leq 14\right\} \cup\left\{y_{1} y_{15}\right\} \\
& \cup\left\{z_{l} v_{l+1} \mid 1 \leq l \leq 4\right\} \cup\left\{z_{1} z_{5}\right\} \cup\left\{w_{1} v_{1}, w_{4} v_{5}, w_{7} v_{4}, w_{10} v_{3}, w_{13} v_{2},\right. \\
& x_{1} w_{15}, x_{2} w_{2}, x_{5} w_{3}, x_{6} w_{5}, x_{9} w_{6}, x_{10} w_{8}, x_{13} w_{9}, x_{14} w_{11}, x_{17} w_{12}, x_{18} w_{14}, \\
& y_{1} x_{20}, y_{2} x_{3}, y_{4} x_{4}, y_{5} x_{7}, y_{7} x_{8}, y_{8} x_{11}, y_{10} x_{12}, y_{11} x_{15}, y_{13} x_{16}, y_{14} x_{19}, \\
& \left.z_{1} y_{15}, z_{2} y_{3}, z_{3} y_{6}, z_{4} y_{9}, z_{5} y_{12}\right\} .
\end{aligned}
$$

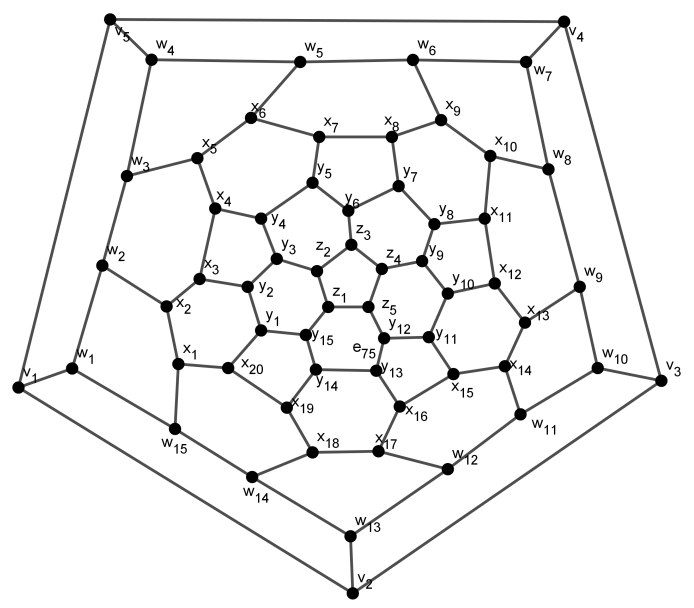

Gambar 4. Graf Buckminsterfullerene

\subsection{Dimensi Metrik pada Graf}

Misalkan $\mathrm{G}$ adalah graf terhubung yang berordo $n$ dengan $u$ dan $v$ adalah titik-titik dalam $G$ maka jarak antara $u$ dan $v$, dinotasikan $d(u, v)$, adalah panjang lintasan terpendek antara kedua titik tersebut di $G$. Misalkan terdapat himpunan terurut $W=\left\{w_{1}, w_{2}, \cdots, w_{k}\right\} \subset V(G)$, dengan $V(G)$ adalah himpunan titik yang tak kosong maka representasi titik $v$ terhadap $W$, dinotasikan $r(u \mid W)$, didefinisikan sebagai k-vektor

$$
r(v \mid W)=\left(d\left(v, w_{1}\right), d\left(v, w_{2}\right), \cdots, d\left(v, w_{k}\right)\right) .
$$

Jika untuk setiap dua titik $u$ dan $v$ di $G$ berlaku bahwa $r(u \mid W) \neq r(v \mid W)$, maka $W$ dinamakan himpunan pemisah untuk $G$. Himpunan pemisah dengan kardinalitas minimum dinamakan himpunan pemisah minimum, dan kardinalitas dari 
himpunan pemisah minimum dinamakan dimensi metrik (metric dimension) dari $G$, dinotasikan

$\operatorname{dim}(G)$ [3]. Teorema 2.1 berikut menjelaskan bahwa satu-satunya graf dengan dimensi metrik 1 adalah graf lintasan $P_{n}$ dengan $n \geq 2$.

Teorema 2.1. [3] Misalkan $G$ adalah graf terhubung dengan banyak titik n. Maka $\operatorname{dim}(G)=1$ jika dan hanya jika $G=P_{n}$ dengan $n \geq 2$.

\section{Dimensi Metrik dari Graf Buckminsterfullerene}

Pada bab ini akan dibahas mengenai dimensi metrik dari graf Buckminsterfullerene dengan 60 titik. Dari Teorema 2.1 dapat dilihat bahwa bahwa satu-satunya graf de-ngan dimensi metrik 1 adalah graf lintasan $P_{n}$ dengan $n \geq 2$, sehingga tidak mungkin graf Buckminsterfullerene memiliki dimensi metrik 1.

Teorema 3.1. Jika $G$ adalah graf Buckminsterfullerene yang memiliki 60 titik maka $\operatorname{dim}(G)=3$.

Bukti. Untuk membuktikan bahwa $\operatorname{dim}(G)=3$ maka akan ditunjukkan bahwa $\operatorname{dim}(G) \leq 3 \operatorname{dan} \operatorname{dim}(G) \geq 3$.

(1) Untuk menunjukkan $\operatorname{dim}(G) \leq 3$, ambil tiga titik pada graf $G$, yaitu $W=$ $\left\{v_{1}, v_{2}, x_{10}\right\}$, seperti yang dapat dilihat pada Gambar 5 .

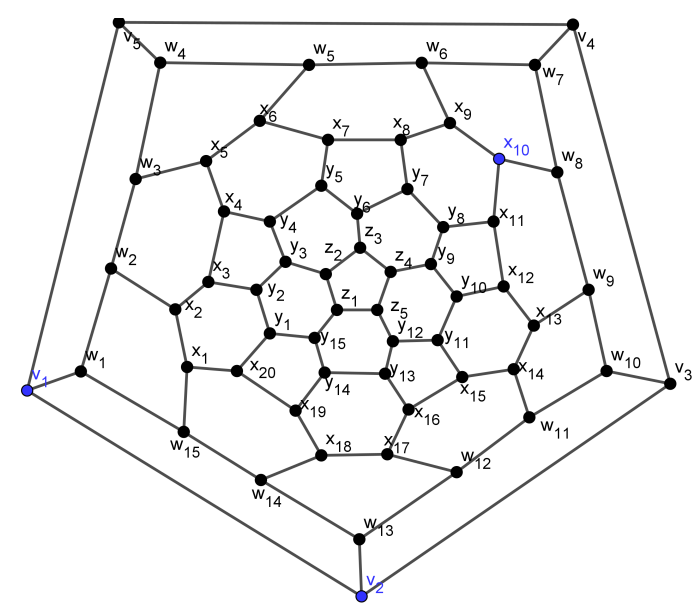

Gambar 5. Graf $G$ dengan $W=\left\{v_{1}, v_{2}, x_{10}\right\}$

Notasikan $r(v \mid W)=\left(d\left(v, v_{1}\right), d\left(v, v_{2}\right), d\left(v, x_{10}\right)\right), \forall v \in V(G)$. Maka di- 
peroleh representasi semua titik pada graf $G$ terhadap $W$ adalah :

$$
\begin{aligned}
& r\left(v_{1} \mid W\right)=(0,1,5), \quad r\left(w_{2} \mid W\right)=(2,3,6), \\
& r\left(v_{2} \mid W\right)=(1,0,5), \quad r\left(w_{3} \mid W\right)=(3,4,5), \\
& r\left(v_{3} \mid W\right)=(2,1,4), \quad r\left(w_{4} \mid W\right)=(2,3,4), \\
& r\left(v_{4} \mid W\right)=(2,2,3), \quad r\left(w_{5} \mid W\right)=(3,4,3), \\
& r\left(v_{5}|| W\right)=(1,2,4), \quad r\left(w_{6} \mid W\right)=(4,4,2), \\
& r\left(w_{1} \mid W\right)=(1,2,6), \quad r\left(w_{7} \mid W\right)=(3,3,2), \\
& r\left(w_{8} \mid W\right)=(4,4,1), \quad r\left(w_{14} \mid W\right)=(3,2,7), \\
& r\left(w_{9} \mid W\right)=(4,3,2), \quad r\left(w_{15} \mid W\right)=(2,3,7), \\
& r\left(w_{10} \mid W\right)=(3,2,3), \quad r\left(x_{1} \mid W\right)=(3,4,8), \\
& r\left(w_{11} \mid W\right)=(4,3,4), \quad r\left(x_{2} \mid W\right)=(3,4,7), \\
& r\left(w_{12} \mid W\right)=(3,2,5), \quad r\left(x_{3} \mid W\right)=(4,5,7), \\
& r\left(w_{13} \mid W\right)=(2,1,6), \quad r\left(x_{4} \mid W\right)=(5,6,6), \\
& r\left(x_{5} \mid W\right)=(4,5,5), \quad r\left(x_{11} \mid W\right)=(6,6,1), \\
& r\left(x_{6} \mid W\right)=(4,5,4), \quad r\left(x_{12} \mid W\right)=(6,5,2), \\
& r\left(x_{7} \mid W\right)=(5,6,3), \quad r\left(x_{13} \mid W\right)=(5,4,3), \\
& r\left(x_{8} \mid W\right)=(6,6,2), \quad r\left(x_{14} \mid W\right)=(5,4,4), \\
& r\left(x_{9} \mid W\right)=(5,5,1), \quad r\left(x_{15} \mid W\right)=(6,5,5), \\
& r\left(x_{10} \mid W\right)=(5,5,0), \quad r\left(x_{16} \mid W\right)=(5,4,6), \\
& r\left(x_{17} \mid W\right)=(4,3,6), \quad r\left(y_{3} \mid W\right)=(6,7,6), \\
& r\left(x_{18} \mid W\right)=(4,3,7), \quad r\left(y_{4} \mid W\right)=(6,7,5), \\
& r\left(x_{19} \mid W\right)=(5,4,8), \quad r\left(y_{5} \mid W\right)=(6,7,4), \\
& r\left(x_{20} \mid W\right)=(4,5,9), \quad r\left(y_{6} \mid W\right)=(7,8,4), \\
& r\left(y_{1} \mid W\right)=(5,6,8), \quad r\left(y_{7} \mid W\right)=(7,7,3), \\
& r\left(y_{2} \mid W\right)=(5,6,7), \quad r\left(y_{8} \mid W\right)=(7,7,2), \\
& r\left(y_{9} \mid W\right)=(8,7,3), \quad r\left(y_{15} \mid W\right)=(6,6,7), \\
& r\left(y_{10} \mid W\right)=(7,6,3), \quad r\left(z_{1} \mid W\right)=(7,7,6), \\
& r\left(y_{11} \mid W\right)=(7,6,4), \quad r\left(z_{2} \mid W\right)=(7,8,6), \\
& r\left(y_{12} \mid W\right)=(7,6,5), \quad r\left(z_{3} \mid W\right)=(8,9,5), \\
& r\left(y_{13} \mid W\right)=(6,5,6), \quad r\left(z_{4} \mid W\right)=(9,8,4), \\
& r\left(y_{14} \mid W\right)=(6,5,7), \quad r\left(z_{5} \mid W\right)=(8,7,5) .
\end{aligned}
$$

Karena setiap titik pada $G$ memiliki representasi yang berbeda, maka $W$ adalah himpunan pemisah, sehingga diperoleh batas atas dari graf $G$ adalah 3 , maka dengan demikian

$$
\operatorname{dim}(G) \leq 3 .
$$


(2) Akan ditunjukkan $\operatorname{dim}(G) \geq 3$ yaitu dengan menunjukkan bahwa untuk sebarang kemungkinan $W$ dengan $|W|=2$, akan selalu terdapat minimal dua titik dengan representasi yang sama. Salah satu contoh himpunan $W$ tersebut dapat dilihat pada Gambar 6. Berikut adalah beberapa kasus yang mungkin terjadi:

Kasus 1. Ambil dua titik sebarang di $C_{5}$. Misalkan $W=\left\{v_{i}, v_{j}\right\}$.

(a) $\left\{v_{i}, v_{j}\right\}$ dengan $j=(i+1) \bmod 5$, untuk $i \in\{1,2,3,4,5\}$. Misalkan $W_{1}=\left\{v_{1}, v_{2}\right\}$, sehingga diperoleh:

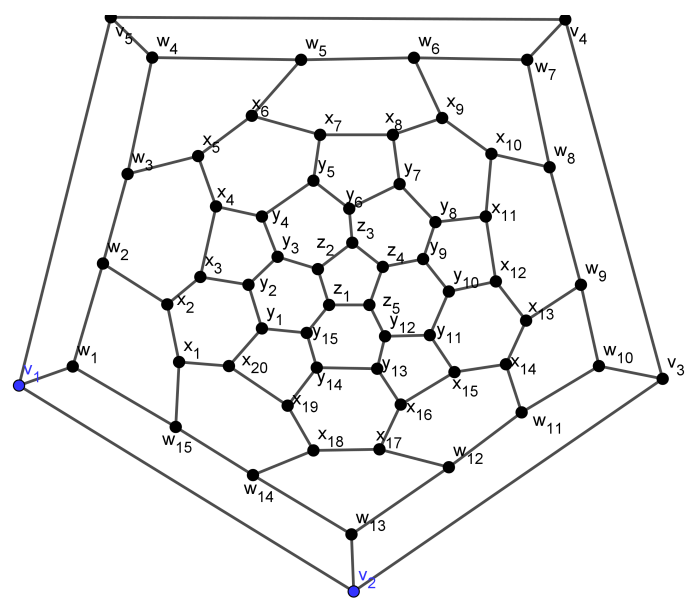

Gambar 6. Graf $G$ dengan $W_{1}=\left\{v_{1}, v_{2}\right\}$

$$
r\left(v_{5} \mid W_{1}\right)=(1,2), \quad r\left(w_{1} \mid W_{1}\right)=(1,2) .
$$

Karena terdapat dua titik yang memiliki representasi yang sama pada graf $G$ tersebut yaitu titik $v_{5}$ dan titik $w_{1}$, maka $W_{1}$ bukan himpunan pemisah. Pengambilan $W_{1}=\left\{v_{1}, v_{2}\right\}$ akan serupa pembuktiannya jika diambil himpunan $\left\{v_{2}, v_{3}\right\},\left\{v_{3}, v_{4}\right\},\left\{v_{4}, v_{5}\right\}$, atau $\left\{v_{5}, v_{1}\right\}$ maka akan terdapat dua titik di $G$ yang memiliki representasi yang sama sehingga $W_{1}$ bukan himpunan pemisah.

(b) $\left\{v_{i}, v_{j}\right\}$ dengan $j=(i+2) \bmod 5$, untuk $i \in\{1,2,3,4,5\}$. Misalkan $W_{2}=\left\{v_{1}, v_{3}\right\}$, diperoleh:

$$
r\left(w_{3} \mid W_{2}\right)=(3,4), \quad r\left(w_{5} \mid W_{2}\right)=(3,4),
$$

sehingga $W_{2}$ bukan himpunan pemisah. Kasus yang serupa terjadi untuk himpunan $\left\{v_{2}, v_{4}\right\},\left\{v_{3}, v_{5}\right\},\left\{v_{4}, v_{1}\right\}$, atau $\left\{v_{5}, v_{2}\right\}$.

Pembuktian dari Kasus 2 sampai dengan Kasus 15 serupa dengan Kasus 1. Hal yang membedakan adalah pengambilan dua titik yang ingin diuji representasinya, yaitu:

Kasus 2. Ambil dua titik sebarang di $C_{15}$. Misalkan $W=\left\{w_{i}, w_{j}\right\}$. 
(a) $\left\{w_{i}, w_{j}\right\}$ dengan $j=(i+1) \bmod 15$, untuk $i \in\{1,4,7,10,13\}$.

(b) $\left\{w_{i}, w_{j}\right\}$ dengan $j=(i+2) \bmod 15$, untuk $i \in\{1,4,7,10,13\}$.

(c) $\left\{w_{i}, w_{j}\right\}$ dengan $j=(i+3) \bmod 15$, untuk $i \in\{1,4,7,10,13\}$.

(d) $\left\{w_{i}, w_{j}\right\}$ dengan $j=(i+4) \bmod 15$, untuk $i \in\{1,4,7,10,13\}$.

(e) $\left\{w_{i}, w_{j}\right\}$ dengan $j=(i+5) \bmod 15$, untuk $i \in\{1,4,7,10,13\}$.

(f) $\left\{w_{i}, w_{j}\right\}$ dengan $j=(i+6) \bmod 15$, untuk $i \in\{1,4,7,10,13\}$.

(g) $\left\{w_{i}, w_{j}\right\}$ dengan $j=(i+7) \bmod 15$, untuk $i \in\{1,4,7,10,13\}$.

Kasus 3. Ambil dua titik sebarang di $C_{20}$.

(a) Misalkan $W=\left\{x_{i}, x_{j}\right\}$ untuk $i \in\{1,5,9,13,17\}$.
i. $\left\{x_{i}, x_{j}\right\}$ dengan $j=(i+1) \bmod 20$.
ii. $\left\{x_{i}, x_{j}\right\}$ dengan $j=(i+2) \bmod 20$.
iii. $\left\{x_{i}, x_{j}\right\}$ dengan $j=(i+3) \bmod 20$.
iv. $\left\{x_{i}, x_{j}\right\}$ dengan $j=(i+4) \bmod 20$.
v. $\left\{x_{i}, x_{j}\right\}$ dengan $j=(i+5) \bmod 20$.
vi. $\left\{x_{i}, x_{j}\right\}$ dengan $j=(i+6) \bmod 20$.
vii. $\left\{x_{i}, x_{j}\right\}$ dengan $j=(i+7) \bmod 20$.
viii. $\left\{x_{i}, x_{j}\right\}$ dengan $j=(i+8) \bmod 20$.
ix. $\left\{x_{i}, x_{j}\right\}$ dengan $j=(i+9) \bmod 20$.
x. $\left\{x_{i}, x_{j}\right\}$ dengan $j=(i+10) \bmod 20$.

(b) Misalkan $W=\left\{x_{i}, x_{k}\right\}$ untuk $i \in\{2,4,6,8,10,12,14,16,18,20\}$.
i. $\left\{x_{i}, x_{k}\right\}$ dengan $k=(i+1) \bmod 20$.
ii. $\left\{x_{i}, x_{k}\right\}$ dengan $k=(i+2) \bmod 20$.
iii. $\left\{x_{i}, x_{k}\right\}$ dengan $k=(i+3) \bmod 20$.
iv. $\left\{x_{i}, x_{k}\right\}$ dengan $k=(i+4) \bmod 20$.
v. $\left\{x_{i}, x_{k}\right\}$ dengan $k=(i+5) \bmod 20$.
vi. $\left\{x_{i}, x_{k}\right\}$ dengan $k=(i+6) \bmod 20$.
vii. $\left\{x_{i}, x_{k}\right\}$ dengan $k=(i+7) \bmod 20$.
viii. $\left\{x_{i}, x_{k}\right\}$ dengan $k=(i+8) \bmod 20$.
ix. $\left\{x_{i}, x_{k}\right\}$ dengan $k=(i+9) \bmod 20$.
x. $\left\{x_{i}, x_{k}\right\}$ dengan $k=(i+10) \bmod 20$.

(c) Misalkan $W=\left\{x_{i}, x_{l}\right\}$ untuk $i \in\{3,7,11,15,19\}$.
i. $\left\{x_{i}, x_{l}\right\}$ dengan $l=(i+1) \bmod 20$.
ii. $\left\{x_{i}, x_{l}\right\}$ dengan $l=(i+2) \bmod 20$.
iii. $\left\{x_{i}, x_{l}\right\}$ dengan $l=(i+3) \bmod 20$.
iv. $\left\{x_{i}, x_{l}\right\}$ dengan $l=(i+4) \bmod 20$.
v. $\left\{x_{i}, x_{l}\right\}$ dengan $l=(i+5) \bmod 20$.
vi. $\left\{x_{i}, x_{l}\right\}$ dengan $l=(i+6) \bmod 20$.
vii. $\left\{x_{i}, x_{l}\right\}$ dengan $l=(i+7) \bmod 20$.
viii. $\left\{x_{i}, x_{l}\right\}$ dengan $l=(i+8) \bmod 20$.
ix. $\left\{x_{i}, x_{l}\right\}$ dengan $l=(i+9) \bmod 20$.
x. $\left\{x_{i}, x_{l}\right\}$ dengan $l=(i+10) \bmod 20$.

Kasus 4. Ambil dua titik sebarang di $C_{15}^{*}$.

(a) Misalkan $W=\left\{y_{i}, y_{j}\right\}$, untuk $i=1,4,7,10,13$. 
i. $\left\{y_{i}, y_{j}\right\}$ dengan $j=(i+1) \bmod 15$.

ii. $\left\{y_{i}, y_{j}\right\}$ dengan $j=(i+2) \bmod 15$.

iii. $\left\{y_{i}, y_{j}\right\}$ dengan $j=(i+3) \bmod 15$.

iv. $\left\{y_{i}, y_{j}\right\}$ dengan $j=(i+4) \bmod 15$.

v. $\left\{y_{i}, y_{j}\right\}$ dengan $j=(i+5) \bmod 15$.

vi. $\left\{y_{i}, y_{j}\right\}$ dengan $j=(i+6) \bmod 15$.

vii. $\left\{y_{i}, y_{j}\right\}$ dengan $j=(i+7) \bmod 15$.

(b) Misalkan $W=\left\{y_{i}, y_{k}\right\}$, untuk $i \in\{2,5,8,11,14\}$.

i. $\left\{y_{i}, y_{k}\right\}$ dengan $k=(i+1) \bmod 15$.

ii. $\left\{y_{i}, y_{k}\right\}$ dengan $k=(i+2) \bmod 15$.

iii. $\left\{y_{i}, y_{k}\right\}$ dengan $k=(i+3) \bmod 15$.

iv. $\left\{y_{i}, y_{k}\right\}$ dengan $k=(i+4) \bmod 15$.

v. $\left\{y_{i}, y_{k}\right\}$ dengan $k=(i+5) \bmod 15$.

vi. $\left\{y_{i}, y_{k}\right\}$ dengan $k=(i+6) \bmod 15$.

vii. $\left\{y_{i}, y_{k}\right\}$ dengan $k=(i+7) \bmod 15$.

(c) Misalkan $W=\left\{y_{i}, y_{l}\right\}$, untuk $i \in\{3,6,9,12,15\}$.

i. $\left\{y_{i}, y_{l}\right\}$ dengan $l=(i+1) \bmod 15$.

ii. $\left\{y_{i}, y_{l}\right\}$ dengan $l=(i+2) \bmod 15$.

iii. $\left\{y_{i}, y_{l}\right\}$ dengan $l=(i+3) \bmod 15$.

iv. $\left\{y_{i}, y_{l}\right\}$ dengan $l=(i+4) \bmod 15$.

v. $\left\{y_{i}, y_{l}\right\}$ dengan $l=(i+5) \bmod 15$.

vi. $\left\{y_{i}, y_{l}\right\}$ dengan $l=(i+6) \bmod 15$.

vii. $\left\{y_{i}, y_{l}\right\}$ dengan $l=(i+7) \bmod 15$.

Kasus 5. Ambil dua titik sebarang di $C_{5}^{*}$. Misalkan $W=\left\{z_{i}, z_{j}\right\}$.

(a) $\left\{z_{i}, z_{j}\right\}$ dengan $j=(i+1) \bmod 5$, untuk $i \in\{1,2,3,4,5\}$.

(b) $\left\{z_{i}, z_{j}\right\}$ dengan $j=i+2 \bmod 5$, untuk $i \in\{1,2,3,4,5\}$.

Kasus 6. Ambil satu titik sebarang di $C_{5}$ dan satu titik sebarang di $C_{15}$.

Kasus 7. Ambil satu titik sebarang di $C_{5}$ dan satu titik sebarang di $C_{20}$.

Kasus 8. Ambil satu titik sebarang di $C_{5}$ dan satu titik sebarang di $C_{15}^{*}$.

Kasus 9. Ambil satu titik sebarang di $C_{5}$ dan satu titik sebarang di $C_{5}^{*}$.

Kasus 10. Ambil satu titik sebarang di $C_{15}$ dan satu titik sebarang di $C_{20}$.

Kasus 11. Ambil satu titik sebarang di $C_{15}$ dan satu titik sebarang di $C_{15}^{*}$.

Kasus 12. Ambil satu titik sebarang di $C_{15}$ dan satu titik sebarang di $C_{5}^{*}$.

Kasus 13. Ambil satu titik sebarang di $C_{20}$ dan satu titik sebarang di $C_{15}^{*}$.

Kasus 14. Ambil satu titik sebarang di $C_{20}$ dan satu titik sebarang di $C_{5}^{*}$.

Kasus 15. Ambil satu titik sebarang di $C_{15}^{*}$ dan satu titik sebarang di $C_{5}^{*}$.

Berdasarkan Kasus 6 sampai Kasus 15 dapat dilihat bahwa $W_{9}, W_{10}, W_{11}$, $W_{12}, W_{13}, W_{14}, W_{15}, W_{16}, W_{17}, W_{18}$ bukan himpunan pemisah, karena terdapat dua titik yang memiliki representasi yang sama.

Dari Kasus 1 sampai Kasus 15 dapat dilihat bahwa jika $|W|=2$, maka akan selalu terdapat dua titik dengan representasi yang sama sehingga, haruslah

$$
\operatorname{dim}(G) \geq 3 .
$$


Dengan demikian dari (3.1) dan (3.2) dapat disimpulkan bahwa dimensi metrik dari graf Buckminsterfullerene adalah tiga.

\section{Kesimpulan}

Penelitian ini membahas tentang dimensi metrik dari graf $G$ dimana $G$ adalah graf Buckminsterfullerene dengan banyak titik 60. Graf Buckminsterfullerene dapat dilihat sebagai graf yang berasal dari $C_{5} \cup C_{15} \cup C_{20} \cup C_{15}^{*} \cup C_{5}^{*}$ dengan penambahan beberapa sisi, seperti pada Gambar 2.3.2. Dalam penelitian ini diperoleh bahwa dimensi metrik graf Buckminsterfullerene adalah tiga.

\section{Ucapan Terima kasih}

Terima kasih kepada Bapak Narwen, M.Si, Bapak Dr. Admi Nazra, dan Bapak Dr. Ahmad Iqbal Baqi sebagai penguji sehingga penelitian ini dapat terlaksana dengan baik.

\section{Daftar Pustaka}

[1] Akhter, S., dan Farooq, R. 2019. Metric Dimension of Fullerene Graphs. Electronic Journal of Graph Theory and Applications. 7(1) : $91-103$.

[2] Andova,V., Kardos, F., dan Skrekovski, R. 2014. Fullerene Graphs and Some Relevant Graph Invariants. Topics in Chemical Graph Theory, University of Kragujevac and Faculty of Science. Kragujevac. pp:39-54, Mathe-matical Chemistry Monographs.978-86-6009-027-2.

[3] Chartrand, G., Eroh, L., Johnson, M., Oellerman, O. 2000. Resolvability in graphs and the metric dimension of a graph. Discrete Applied Mathematics. (105): $99-113$.

[4] Yadav, B.C., Kumar, R. 2008. Structure Properties and Applications of Fullerene. International Journal of Nanotechnology and Applications. (2): 15 -24 . 